Portland State University

PDXScholar

\title{
Aerobic and Anaerobic Exercise: Analyzing the Benefits of Different Forms of Exercise for Adults Diagnosed with Type 2 Diabetes
}

Mark A. Yakubovich

Portland State University

Follow this and additional works at: https://pdxscholar.library.pdx.edu/honorstheses

Let us know how access to this document benefits you.

\section{Recommended Citation}

Yakubovich, Mark A., "Aerobic and Anaerobic Exercise: Analyzing the Benefits of Different Forms of Exercise for Adults Diagnosed with Type 2 Diabetes" (2017). University Honors Theses. Paper 442. https://doi.org/10.15760/honors.439

This Thesis is brought to you for free and open access. It has been accepted for inclusion in University Honors Theses by an authorized administrator of PDXScholar. Please contact us if we can make this document more accessible: pdxscholar@pdx.edu. 
Aerobic and Anaerobic Exercise: Analyzing the Benefits of Different Forms of Exercise for Adults Diagnosed with Type 2 Diabetes

\author{
by \\ Mark Yakubovich \\ An undergraduate honors thesis submitted in partial fulfillment of the \\ requirements for the degree of \\ Bachelor of Science \\ in \\ University Honors \\ and \\ Health Studies: Physical Activity/Exercise
}

Thesis Adviser

Debra Harris

Portland State University 


\begin{abstract}
This paper explores multiple published articles that will consider the effects of aerobic and anaerobic exercise performed by adult individuals diagnosed with type 2 diabetes mellitus. It will also explore the benefits of combining both forms of exercise and how each compare in terms of glycemic control. This paper will specifically be looking at the benefits of exercise on type 2 diabetes mellitus. I acknowledge that a combination of both exercise and nutrition is optimal for individuals with type 2 diabetes, but this paper is solely looking at the effects of exercise. I will be analyzing the methods used in each study and examine the benefits researchers provide from their results.
\end{abstract}

\title{
Introduction
}

Diabetes is a disease characterized by hyperglycemia resulting from inadequate insulin secretion, reduced insulin action, or both. Type 2 diabetes is associated with reduced insulin action, also known as insulin resistance (Powers \& Howley, 2007). Type 2 diabetes represents about $90 \%$ to $95 \%$ of all diabetes cases and can be linked to obesity and physical inactivity. It was once thought to be a metabolic disorder exclusively for adults, but it has become increasingly more frequent in obese youth (D'Adamo, 2011). In this paper, I will be examining various exercise physiological studies to understand the relationship between argument and evidence of the different effects various forms of exercise has on type 2 diabetes. More specifically, I will be analyzing the effect of aerobic and anaerobic exercise on type 2 diabetes with my focus population being adults over the age of 18 years old. The question I pose is how do the effects of aerobic and anaerobic exercise differ in adults diagnosed with type 2 diabetes? 


\section{What Is Type 2 Diabetes?}

There are two main hormones found in the pancreas, insulin (beta cells), and glucagon (alpha cells). These hormones are used to regulate the human body's blood glucose level (Yach. 2003). The human body is constantly working to maintain homeostasis and the pancreas plays a key role in this. When the blood glucose levels are rising too high, the pancreas releases insulin to communicate with the cells to store glucose. On the opposite side, when the blood glucose levels are decreasing too low, the body releases glucagon to tell the cells to release the stored glucose. A person's blood glucose level is the amount of glucose in the blood. An average blood glucose level will read between $72 \mathrm{mg} / \mathrm{dl}$ and $108 \mathrm{mg} / \mathrm{dl}$. A person with impaired fasting glucose or is pre-diabetic has a blood glucose level between $110 \mathrm{mg} / \mathrm{dl}$ and $125 \mathrm{mg} / \mathrm{dl}$. Somebody who is diabetic will have a blood glucose level of $126 \mathrm{mg} / \mathrm{dl}$ or higher (Yach, 2003). These readings are for a fasting blood glucose level. This means a person's blood glucose level without the influence of food. The human body's blood glucose level has the potential to rise to unsafe levels that can cause damage to blood vessels and neurons if the body is not able to produce insulin or is insulin resistant. In extreme cases, amputations can be caused from too many dead blood cells in the extremities of the body (Powers \& Howley, 2007). An abnormal production of insulin can also be a determinant for whether a person may have a form of diabetes mellitus.

Diabetes mellitus has two types, type I and type II. Type I is an autoimmune disease where the body attacks the beta cells (insulin) and eventually the pancreas produces little to no insulin to regulate the blood glucose level in the body. Type II diabetes is a disease caused by the insulin cells in the pancreas being over-exhausted by storing too much glucose that the receptor proteins decrease, causing insulin resistance. Type II diabetes can also be caused by the pancreas producing inadequate amounts of insulin (Powers \& Howley, 2007). When this occurs, the 
human body is forced to find other ways to maintain homeostasis. When insulin is not able to tell the cells to store glucose, there is an imbalance of glucagon versus insulin and the result is a high blood glucose level. The major causes of insulin resistance are thought to be from obesity and physical inactivity (Powers \& Howley, 2007).

\section{Aerobic vs Anaerobic Exercise}

Aerobic exercise, also known as endurance training, is defined as any exercise designed to increase cardiovascular fitness, often described as an increase in the maximal uptake of oxygen (Madden, 2013). This consists of rhythmic, repeated, and continuous movements of the same large muscle groups for at least $10 \mathrm{~min}$ at a time. When performed at sufficient intensity and frequency, this type of exercise increases cardiorespiratory fitness (Sigal, 2004). Aerobic exercise increases heart rate and breathing rate by stimulating the heart and lungs to keep the body maintained during exercise. Forms of aerobic exercise are running, swimming, biking, cross country skiing, and many others. This type of exercise requires oxygenated blood to be delivered by the heart to working muscles. Oxygen, once inside the muscles, is used to burn fat and carbohydrates for energy to combat the need during exercise (Powers, 2007).

Anaerobic exercise, also known as resistance training, is defined as any exercise designed to increase muscle mass and muscular strength (Madden, 2013). Activities that use muscular strength might involve moving a weight or working against a resistive load. When performed with regularity and moderate to high intensity, resistance exercise increases muscular fitness (Sigal, 2004). Some examples of anaerobic exercises are weight lifting and sprinting. Many anaerobic exercises involve a short duration of high intensity movements. This type of exercise focuses on building muscular strength and improved musculoskeletal function. 


\section{Methods}

Exercise intensity was measured in kilocalories burned per minute of activity or in a unit called the metabolic equivalent (MET). A MET is defined as the ratio of the metabolic rate during exercise to the metabolic rate at rest (Bassuk, 2005). Bassuk used this measurement to set standards for moderate-intensive activities and vigorous exercise activities. Moderate-intensive activities, such brisk walking, are those that burn 3.5-7 kcal/min, or those that expend 3-6 METs. Vigorous activities, such as running, are those that burn $>7 \mathrm{kcal} / \mathrm{min}$ or expend $>6 \mathrm{METs}$ (Bassuk, 2005). Bassuk designed an observational cohort study that measured the effects of aerobic exercise at specific pace for a set time. Even though the focus of the study was on aerobic exercises, Bassuk understood that the combination of both aerobic and anaerobic exercise would be most beneficial for somebody diagnosed with type II diabetes mellitus.

Maiorana designed a program that tested not just aerobic exercise, but a combination of both aerobic and anaerobic exercises and their added effects on a person diagnosed with type II diabetes. Their study assigned subjects to an 8-week exercise training program or a non-training period by random selection. They were instructed not to undertake any formal exercise or change their level of general physical activity during these periods. Experimental measures were assessed at the beginning of the study, after 8 weeks and 16 weeks after entry. These measures included respiratory gas exchange assessment at submaximal steady-state and peak workloads during an incremental bicycle ergometer test, muscular strength measurement and anthropometric assessment of body composition. Antecubital venous blood was drawn for determination of fasting blood glucose, glycated hemoglobin and plasma lipid concentrations. Familiarization exercise test and strength assessments were taken during a 2 week lead-in period before the random selection of the experimental and control group (Maiorana, 2002). The 
conditioning phase of each session involved circuit training. An exercise circuit consisted of seven resistance exercises alternated with eight aerobic exercise stations. Each exercise was performed for 45 seconds and had 15 seconds to move to the next station. At the end of a circuit, subjects spent 5 minutes walking on a treadmill. The cardio exercises between resistance stations were designed to maintain exercise heart rate within the training zone and to facilitate changes in cardiorespiratory fitness. Intensity and duration of the exercise training increased throughout the 8 weeks of the program. Intensity and duration were increased by increasing the number of exercise circuits from 1 to 3 and then by increasing resistance, cycling and treadmill load (Maiorana, 2002).

Sigal designed a 26-week, randomized, controlled trial that tested the effects of aerobic exercise, anaerobic exercise and the combination of both aerobic and anaerobic exercise. Participants initially started a pre-study phase where they performed 15 to 20 minutes of aerobic exercise and 1 or 2 sets of 8 resistance exercises, at moderate intensity. Only participants who attended 10 or more of the scheduled 12 run-in sessions were eligible for randomization. After the 4-week pre-study phase, previously inactive persons with type 2 diabetes were randomly assigned to 1 of 4 groups: aerobic training, resistance training, combined aerobic and resistance training, or a control group that reverted to pre-study exercise levels (sigal, 2007). Exercise group participants exercised 3 times weekly, and training progressed gradually in duration and intensity. The aerobic training group exercised on treadmills or cycle ergometers. Heart rate monitors were used to adjust workload to achieve the target heart rate. Participants progressed from 15 to 20 minutes per session at $60 \%$ of the maximum heart rate to 45 minutes per session at $75 \%$ of the maximum heart rate. The resistance training group performed 7 different exercises on weight machines each session, progressing to 2 to 3 sets of each exercise at the maximum weight 
that could be lifted 7 to 9 times. The combined exercise training group did the full aerobic training program plus the full resistance training program to ensure an adequate dose of each type of exercise. The frequency of direct supervision by trainers was the same in all exercise groups. Control participants were asked to revert to pre-study activity levels.

\section{Results}

Physiologically, aerobic exercise improved glycemic control in type II diabetes through increasing insulin sensitivity (Madden, 2013). Anaerobic exercise improved bone density, the preservation of musculoskeletal function and improved glycemic control, but through a different mechanism. Glycemic control was improved through increasing muscle mass and by increasing the glucose transporter expression (GLUT-4) (Madden, 2013). By combining both aerobic and anaerobic exercise, glycemic control was improved through both mechanisms of increasing insulin sensitivity, muscle mass and increasing the glucose transporter expression (GLUT-4), but also reduced body weight, decreased insulin resistance, decreased blood pressure and inflammation (Bassuk, 2005).

The primary outcome was the absolute change in hemoglobin value between baseline and the end of the 6-month supervised exercise period. Secondary outcomes were plasma lipid values, blood pressure level, and body composition (Sigal, 2007). Current guidelines recommend that patients with type 2 diabetes should perform at least 150 minutes per week of moderateintensity aerobic exercise and should perform resistance exercise 3 times per week (Umpierre, 2011).

\section{Summary of Argument}

The study designs for both aerobic and anaerobic exercise were similar in setup. The main difference between the two were which type of exercise was the focus of the research. Each 
researcher had the study participants workout in circuits that had the different type of workouts that correlated to either aerobic exercise or anaerobic exercise. Some studies alternated aerobic and anaerobic exercise in the circuit if they were testing the effects of an individual performing both aerobic and anaerobic exercises. There was an agreement among the researchers that physical activity positively affected metabolic and cardiovascular health. The ongoing debate is on the amount, intensity, duration, and type of exercise an individual with diabetes should perform for optimal health benefits. Resistance training has shown positive effects on muscle mass, muscular strength and level of function, while aerobic training has shown positive effects on cardiovascular endurance. The studies I researched suggested that a combination of aerobic and anaerobic exercise be best for individuals with type 2 diabetes for optimal results. Aerobic and anaerobic exercise both improved glycemic control, but the combination of the two provided significant results when compared to just aerobic or anaerobic exercise alone.

\section{Conclusion}

In summary, aerobic training and resistance training alone each led to improvements in glycemic control, and combined aerobic and resistance training had effects that were greater than those of either method alone. These effects were more powerful among individuals with poor glycemic control at baseline. The research being conducted for adults on the exercise prescription needed to impact their type 2 diabetes is vast. The next step needed is to turn the focus on today's youth. In 1990, less than 3\% of all cases of type 2 diabetes mellitus were youth under the age of 18 years old. As of 2005, that percentage had increased to $45 \%$ (Pinhas-Hamie, 2005). The prevalence of youth diagnosed with type 2 diabetes has become an epidemic in today's society. As of 2012, over 22 million children under the age of five years old were obese (Deckelbaum, 2012). This research with the target population being youth under the age of 18 
years old, can be a step forward to decreasing the prevalence of youth diagnosed with type 2 diabetes.

\section{Bibliography}

- Bassuk, S. S., \& Manson, J. E. (2005). Epidemiological evidence for the role of physical activity in reducing risk of type 2 diabetes and cardiovascular disease.Journal of Applied Physiology (Bethesda, Md.: 1985), 99(3), 1193-1204.

https://doi.org/10.1152/japplphysiol.00160.2005

- Danaei, G., Finucane, M. M., Lu, Y., Singh, G. M., Cowan, M. J., Paciorek, C. J., ... Ezzati, M. (2011). National, regional, and global trends in fasting plasma glucose and diabetes prevalence since 1980: systematic analysis of health examination surveys and epidemiological studies with 370 country-years and 2.7 million participants. The Lancet, 378(9785), 31-40.

- D’Adamo, E., \& Caprio, S. (2011). Type 2 Diabetes in Youth: Epidemiology and Pathophysiology. Diabetes Care, 34(Supplement 2), S161-S165.

- Deckelbaum, R. J. (2012, September 6). Childhood Obesity: The Health Issue.Obesity Research, 9(S11), 239-243.

- Ebbeling, C. B. (2012, August 10). Childhood obesity: Public-health crisis, common sense cure. The Lancet, 360(9331), 473-482.

- Hensley, L. D. (2000). Current Status of Basic Instruction Programs in Physical Education at American Colleges and Universities.Journal of Physical Education, Recreation \& Dance, 71(9), 30-36. https://doi.org/10.1080/07303084.2000.10605719

- Joens-Matre, R. R., Welk, G. J., Calabro, M. A., Russell, D. W., Nicklay, E., \& Hensley, L. D. (2008). Rural-Urban Differences in Physical Activity, Physical Fitness, and 
Overweight Prevalence of Children.The Journal of Rural Health, 24(1), 49-54.

https://doi.org/10.1111/j.1748-0361.2008.00136.x

- Madden, K. (2013). Evidence for the benefit of exercise therapy in patients with type 2 diabetes. Diabetes, Metabolic Syndrome and Obesity: Targets and Therapy, 233. https://doi.org/10.2147/DMSO.S32951

- Maiorana, A., O’Driscoll, G., Goodman, C., Taylor, R., \& Green, D. (2002). Combined aerobic and resistance exercise improves glycemic control and fitness in type 2 diabetes. Diabetes Research and Clinical Practice,56(2), 115-123. https://doi.org/10.1016/S0168$\underline{8227(01) 00368-0}$

- McCormack, L. A., \& Meendering, J. (2016). Diet and Physical Activity in Rural vs Urban Children and Adolescents in the United States: A Narrative Review. Journal of the Academy of Nutrition and Dietetics,116(3), 467-480. https://doi.org/10.1016/j.jand.2015.10.024

- Mullooly, C. A., \& Kemmis, K. L. (2005). Diabetes Educators and the Exercise Prescription. Diabetes Spectrum, 18(2), 108-113. https://doi.org/10.2337/diaspect.18.2.108

- Pinhas-Hamiel, O., \& Zeitler, P. (2005). The global spread of type 2 diabetes mellitus in children and adolescents. The Journal of Pediatrics, 146(5), 693-700.

- Powers, S. K., \& Howley, E. T. (2007). Exercise physiology: Theory and application to fitness and performance. Boston: McGraw-Hill.

- Sigal, R. J., Kenny, G. P., Boulé, N. G., Wells, G. A., Prud'homme, D., Fortier, M., ... Jaffey, J. (2007). Effects of Aerobic Training, Resistance Training, or Both on Glycemic 
Control in Type 2 Diabetes A Randomized Trial. Annals of Internal Medicine, 147(6), $357-369$.

- Sigal, R. J., Kenny, G. P., Wasserman, D. H., \& Castaneda-Sceppa, C. (2004). Physical Activity/Exercise and Type 2 Diabetes. Diabetes Care, 27(10), 2518-2539.

- Stewart, K. J. (2002). Exercise training and the cardiovascular consequences of type 2 diabetes and hypertension: plausible mechanisms for improving cardiovascular health. JAMA, 288(13), 1622-1631.

- Strong, W. B., Malina, R. M., Blimkie, C. J. R., Daniels, S. R., Dishman, R. K., Gutin, B., ... Trudeau, F. (2005). Evidence Based Physical Activity for School-age Youth. The Journal of Pediatrics,146(6), 732-737. https://doi.org/10.1016/j.jpeds.2005.01.055

- Umpierre, D., Ribeiro, P. A. B., Kramer, C. K., Leitão, C. B., Zucatti, A. T. N., Azevedo, M. J., ... Schaan, B. D. (2011). Physical Activity Advice Only or Structured Exercise Training and Association With HbA1c Levels in Type 2 Diabetes: A Systematic Review and Meta-analysis. JAMA, 305(17), 1790-1799.

- Yach, D. (2003). Screening For Type 2 Diabetes (Rep.). 